\title{
Fatty Acid Composition, Total Phenolic Content and Antioxidant Activity of Grape Seed Oils Obtained by Cold- Pressed and Solvent Extraction
}

\author{
Dilsat Bozdogan Konuskan ${ }^{1, *}$, Onder Kamiloglu², Ozge Demirkeser \\ ${ }^{1}$ Mustafa Kemal University, Faculty of Agriculture, Department of Food Engineering, 31034, Hatay, TURKEY. \\ ${ }^{2}$ Mustafa Kemal University, Faculty of Agriculture, Department of Horticulture, 31034, Hatay, TURKEY.
}

\begin{abstract}
Aim: The aim of this study was to determine the influence of two different extraction methods on the fatty acid composition, total phenolic content and antioxidant activity of grape seed oils obtained from 5 different varieties. Materials and Methods: The seeds of the Syrah, Merlot, Sangiovese, Cabernet Sauvignon, Sauvignon Blanc grape varieties were used in this study. Oil extraction was carried out by Soxhlet extraction and coldpressed extraction methods. Results: The most abundant fatty acids in the grape seed oils that were obtained were linoleic acid, oleic acid and palmitic acid ranging from 64.80 to $68.64 \%, 18.41$ to $21.58 \%$ and 7.08 to $8.23 \%$, respectively. The linoleic and palmitic acid values that were determined in the grape seed oils obtained by solvent extraction were higher than those for the grape seed oils obtained from the cold-pressed samples. The total phenolic content and antioxidant activity of the grape seed oils varied between 115.68 and $317.71 \mathrm{mg} \mathrm{GAE} / \mathrm{kg}, 7.14$ and $34.46 \%$ as DPPH radical scavenging activities, respectively. Conclusion: The total phenolic content and antioxidant activity values for the grape seed oils obtained by solvent extraction were higher than those determined in the grape seed oils obtained by cold-pressing.
\end{abstract}

Key words: Grape seed oil, Fatty acid composition, Phenolic content, Antioxidant activity, Extraction method.

\section{INTRODUCTION}

Grapes, the berries of Vitis vinifera L. ssp sativa, are one of the major fruit crops cultivated in many areas of the World., ${ }^{1,2}$ Turkey has production of 4 million tons of grapes, as the world's sixth-largest grape-producing country according to the data in $2017 .{ }^{3}$ During the production of some products such as wine, vinegar, grape juice from grapes are obtained large quantity pomace. ${ }^{4,5}$ Grape pomace accounts for $20 \%$ of grape and it is composed of seeds, skin and stems. ${ }^{6}$ Grape seeds, corresponding to $38-52 \%$ on a dry matter basis, are significant agricultural and industrial wastes. ${ }^{7}$ Grape seeds contain from 8 to $20 \%$ of oil depending on the extraction methods and variety. ${ }^{8}$ Grape seed oils include about poly- and monounsaturated fatty acids, as in the amount of $90 \%$, par- ticularly of linoleic acid (58-78\%, C18:2) followed by oleic acid (3-15\%, C18:1) and minor amounts of saturated fatty acids $(10 \%){ }^{6,8}$ Polyunsaturated fatty acids such as linoleic acid are referred to in the literature as desirable compounds in the human diet because of their effect in reducing the risk of coronary heart diseases and cancer. ${ }^{2} \mathrm{On}$ the other hand, oleic acid is considered to reduce the levels of low density lipoproteins and prevent artherosclerosis. ${ }^{1,2}$ Furthermore, grape seed oil contains minor components such as phenolic compounds. ${ }^{6,9}$ The benefits of phenolic compounds on human health are correlated with their antioxidant activity. ${ }^{10}$ Phenolic compounds are reported to be beneficial for oil conservation due to their increasing oil oxida-
Submission Date: 23-04-2018; Revision Date: 14-08-2018; Accepted Date: 23-10-2018

DOI: 10.5530/ijper.53.1.19 Correspondence: Dr. Dilsat Bozdogan Konuskan

Mustafa Kemal University, Faculty of Agriculture, Department of Food Engineering, 31034, Hatay, TURKEY.

Phone: +90 3262455836 E-mail: dilsat@mku.edu.tr

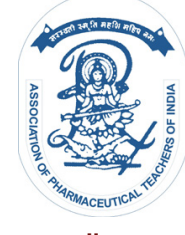

www.ijper.org 
tive stability. ${ }^{1,6}$ Grape seed oil has been recognized as a high-quality oil for infants and elderly people. ${ }^{5,11} \mathrm{Soft}$ fruity taste, high smoking point $\left(210-230^{\circ} \mathrm{C}\right)$, with not a significant increase in its viscosity when it is used as a frying oil, being digestible to great extent are the main properties that describe the good qualities of grape seed oil. ${ }^{12,13}$ Grape seed oil is obtained from cold-pressing, solvent extraction (Soxhlet), instrumental methods (microwave, ultrasound, supercritical fluid extraction), enzyme assisted aqueous extraction, infrared, $\mathrm{X}$ ray absorption. ${ }^{13-17}$ The cold-pressing method is a method of oil extraction without heat and chemical treatment and therefore, it may keep health beneficial components such as antioxidative phenolic compounds. ${ }^{6,18}$ Even though the yield is lower when it is compared to conventional solvent extraction, it is not harmful for the health of the product and it is a safer method due to the fact that there is no solvent residues in the oil. ${ }^{1}$

To our knowledge, there is no study about the effects of different extraction methods on the fatty acid composition, total phenolic content and antioxidant activity of grape seed oil. Therefore, the aim of this study was to determine the influence of two different extraction methods on the fatty acid composition, total phenolic content and antioxidant activity of grape seed oils obtained from 5 different varieties.

\section{MATERIALS AND METHODS}

The seeds of the Syrah, Merlot, Sangiovese, Cabernet Sauvignon, Sauvignon Blanc grape varieties were used in this study. The grapes were collected at harvesting time (13-26 July) from the commercial wine grapes production vineyard of the province of Hatay in the Eastern Mediterranean Region in Turkey in 2016. The grapevine establishment is located at $36^{\circ} 25.5^{\prime} \mathrm{K}, 36^{\circ} 15.7^{\prime}$ $\mathrm{D}$ and its altitude from the sea is $114 \mathrm{~m}$. The cultivars were grafted on 41B rootstock and embedded in 2X1 $\mathrm{m}$ spaces in 2008 and trained in a single guyot system.

\section{Chemicals}

All the chemicals that were used in the experiments were of analytical grade. Gallic acid, 2,2' -diphenyl-1 picryhydrazyl (DPPH), Folin-Ciocalteu's reagent, sodium carbonate, methanol, n-hexane, diethyl ether, were obtained from Merck (Germany) and Sigma-Aldrich (Germany). The fatty acid methyl ester (FAME) mixes were obtained from Supelco (Bellefonte, USA).

\section{Water and Oil Content}

The water content of the grape seeds were calculated based on the method by Rombaut et al. ${ }^{6}$ The oil content of the grape seeds was determined based on the method described by the American Oil Chemists' Society (AOCS) Official Methods Am $2-93^{19}$ by the Soxhlet extraction method using $\mathrm{n}$-hexane at $80^{\circ} \mathrm{C}$ for $6 \mathrm{~h}$.

\section{Oil Extraction}

Oil extraction was carried out by Soxhlet extraction and cold-pressed extraction methods. Oil extraction by the Soxhlet method was as mentioned in oil content.

\section{Cold-pressed Extraction}

Oil extraction by the cold-pressed method was performed on a screw press (Kocmaksan, Turkey). The pressing was conducted without external heating. The oily phase was centrifuged at $5 \mathrm{~min}, 3000 \mathrm{rpm}$ and room temperature to separate the oil from the sediment.

Both the Soxhlet oil and the cold-pressed oil were stored at $+4^{\circ} \mathrm{C}$ until analyses which were duplicated.

\section{FattyAcid Composition}

The fatty acid methyl esters (FAMEs) were prepared from the grape seed oils using a cold transmethylation by shaking a solution of $0.2 \mathrm{~g}$ oil and $3 \mathrm{ml}$ of hexane with $0.4 \mathrm{ml}$ of $2 \mathrm{~mol} / \mathrm{L}$ methanolic potassium hydroxide. $^{20}$

The analysis of the FAME was performed by an Agilent gas chromatography system (Agilent 6850, USA) using a hydrogen flame ionization detector (FID) and a capillary column DB23 (60 m length $90.25 \mathrm{~mm}$ i.d. and 0.25 $\mu \mathrm{m}$ film thickness). The temperatures of the detector and the injector were set at 230 and $280^{\circ} \mathrm{C}$, respectively. Helium was employed as carrier gas with a flow rate of $1 \mathrm{ml} / \mathrm{min}$ and the split ratio was 1:50. The injection volume was $1 \mu \mathrm{l}$. The results were expressed as a relative area percentage of total fatty acid methyl esters. The fatty acids were determined by comparing their retention times to those of the reference compounds.

\section{Total Phenolic Contents}

The total phenolic contents (TPC) of the grape seed oils were calculated by using the Folin ciocalteau colorimetric method according to the method described by Bail et $a l^{8}$ with some modifications. For the extraction of the phenols from oil 80:20, methanol: water $(3 \mathrm{ml})$ was added to $1 \mathrm{~g}$ of each oil followed by vortex for two min and centrifuged for $5 \mathrm{~min}$ at $3000 \mathrm{rpm}$. The extraction was carried out three times. All the methanolic extracts were combined and concentrated until dryness. After the extraction process, $0.2 \mathrm{ml}$ of the phenolic extract was mixed with $1 \mathrm{a} \mathrm{ml}$ of the Folin-Ciocalteu reagent. $3 \mathrm{ml}$ of the saturated sodium carbonate solution $(10 \%)$ was added to this mixture. After vigorous shaking, the volume of the solution was increased to $10 \mathrm{ml}$ with distilled water. The mixture was left to stand for $30 \mathrm{~min}$ 
in the dark at room temperature. The absorbance was recorded at $765 \mathrm{~nm}$ in a UV-Vis spectrophotometer (Hitachi U-1900, Japan). Quantification was carried out using a standard curve built with 25-50-100-200 mg/l prepared in an aqueous solution of methanol $(70 \%)$ The results were expressed as milligrams of gallic acid equivalents per kilogram of oil (mg GAE/ kg).

\section{Antioxidant Activity}

The antioxidant activity (free radical scavenging capacity) of the grape seed oil phenolic extracts was determined by using the method of the 2,2-diphenyl-1-picrylhydrazil (DPPH) radical according to the procedure of Brand Williams et al. ${ }^{21}$ with some modifications. Briefly, $1 \mathrm{ml}$ of extracts was diluted with $1.9 \mathrm{ml}$ DPPH methanolic solutions. After $60 \mathrm{~min}$ of incubation in the dark at room temperature, the absorbance was measured at $515 \mathrm{~nm}$ against a blank $(\mathrm{MeOH})$.

The percentage of inhibition was calculated from the following equation:

$\%$ Inhibition $(\mathrm{DPPH})=\left[\left(\mathrm{Abs}_{\text {Control }}-\mathrm{Abs}_{\text {Sample }} / \mathrm{Abs}_{\mathrm{Control}}\right]\right.$ $\mathrm{x} 100$

\section{Statistical analysis}

The experiment was set up as a two-factor completely randomized design. Each treatment included 3 replicates. The variance analyses of the obtained data were made by using the Mstat-C computer software. The differences between the averages were evaluated by a Tukey test at $0.05 .^{22}$

\section{RESULTS AND DISCUSSION}

\section{Water and Oil Content}

The water and oil contents of the grape seeds with different varieties are given in Table 1. As shown in Table 1 , the water content of the grape seeds ranged from 7.94 (Sauvignon Blanc) to $9.94 \%$ (Sirah). The results indicated that the water content of the grape seeds showed significant differences depending on the variety $(\mathrm{P}<0.05)$. The oil content of the grape seed was around 7 to $20 \% .^{23}$ The oil contents of the grape seeds were between 4.95\% (Sangiovese) and 7.77\% (Sirah). Our results were lower than those obtained by Göktürk Baydar and Akkurt, ${ }^{4}$ Lachman et al. ${ }^{2}$ and Apaydin et al. ${ }^{5}$ In another study on Turkish grape seeds, the results were higher, varying between 12.35 in Kalecik Karas1 and $16.00 \%$ in Hasandede. ${ }^{24}$ The differences between the values of grape seed oil content depended on the variety and the cultivation conditions ${ }^{20}$ and extraction methods. ${ }^{8}$ Lutterodt $e t$ al. ${ }^{1}$, stated that oil yield with the cold-pressed method was lower than that with solvent extraction.

\section{Fatty acid composition}

The fatty acid composition of the grape seed oils obtained by the cold-pressed and solvent extraction methods were shown in in Table 2. Linoleic (C18:2), oleic (C18:1), palmitic (C16:0) and stearic (C18:0) were the major fatty acids in the grape seed oils. The minor fatty acids were palmitoleic (C16:1), linolenic (C18:3), arachidic (C20:0) and gadoleic (C20:1) acid. Linoleic acid was the most abundant fatty acid in all the grape seed oils, ranging from $64.80 \%$ in Sirah to $68.64 \%$ in Merlot. The linoleic acid content of the grape seed oils showed significant $(P<0.05)$ variations across the varieties (except for the Sauvignon Blanc and Sangiovese variations). Furthermore, the linoleic acid content of all the grape seed oils was significantly $(P<0.05)$ influenced by the extraction methods. The results indicated that the linoleic acid content of the grape seed oils obtained by the solvent extraction $(67.54 \%)$ method was higher than that of the grape seed oils obtained by the cold-pressed method $(66.16 \%)$. The interaction between the variety and the extraction method was found to be significant among all the fatty acids of the studied grape seed oils. A-D express significant statistical differences between cultivars. X-Y letters express significant statistical differences between extraction methods. Different small letters express significant statistical differences in the interaction of cultivars by the extraction methods of $\mathrm{X}$ (Tukey test $P<0.05$ ), N.S: Not significant.

Tangolar et al. ${ }^{25}$ stated that the ranges of fatty acids in the grape seeds were 62.5 in Alicante Bouschet to $69.24 \%$ in Muscat of Hamburg varieties for linoleic acid. Additionally, Fernandes et $_{\text {al. }}{ }^{7}$ reported that the linoleic acid content of Portuguese grape seed oils was in the range of $63.0-73.1 \%$. Our results were in good agreement with those obtained by Tangolar et al. ${ }^{25}$ and Fernandes $e t$ al..$^{7}$ The oleic acid content in our study varied between $18.41 \%$ in Sauvignon Blanc and $21.58 \%$ in Sirah.

\section{Table 1: Water and oil contents of grape seeds.}

\begin{tabular}{|c|c|c|}
\hline Cultivar & $\begin{array}{c}\text { Oil Content } \\
(\%)\end{array}$ & $\begin{array}{c}\text { Water content } \\
\text { (\%) }\end{array}$ \\
\hline Sirah & $7.77 \mathrm{a}^{*}$ & $9.94 \mathrm{c}$ \\
\hline Merlot & $5.65 \mathrm{bc}$ & $9.10 \mathrm{bc}$ \\
\hline Sangiovese & $4.95 \mathrm{c}$ & $8.77 \mathrm{ab}$ \\
\hline Cabernet Sauvignon & $5.65 \mathrm{bc}$ & $8.08 \mathrm{a}$ \\
\hline Sauvignon Blanc & $7.10 \mathrm{ab}$ & $7.94 \mathrm{a}$ \\
\hline D\%5 & 2.11 & 0.85 \\
\hline
\end{tabular}

*: The differences between the means marked with different letters $(p<0.05)$ 


\begin{tabular}{|c|c|c|c|c|c|c|c|c|c|}
\hline Cultivar & $\begin{array}{l}\text { Extraction } \\
\text { method }\end{array}$ & $\begin{array}{l}\text { Palmitic } \\
\text { (C16:0) }\end{array}$ & $\begin{array}{l}\text { Palmitoleic } \\
\text { (C16:1) }\end{array}$ & $\begin{array}{l}\text { Stearic } \\
\text { (C18:0) }\end{array}$ & $\begin{array}{c}\text { Oleic } \\
\text { (C18:2) }\end{array}$ & $\begin{array}{l}\text { Linoleic } \\
\text { (C18:2) }\end{array}$ & $\begin{array}{l}\text { Linolenic } \\
\text { (C18:3) }\end{array}$ & $\begin{array}{l}\text { Arachidic } \\
\text { (C20:0) }\end{array}$ & $\begin{array}{l}\text { Gadoleic } \\
\text { (C20:1) }\end{array}$ \\
\hline \multirow{2}{*}{ Sirah } & Solvent & $8.270 \mathrm{~b}$ & $0.247 c$ & $4.110 d$ & $21.567 \mathrm{a}$ & $64.977 \mathrm{f}$ & $0.327 \mathrm{bc}$ & $0.137 f$ & $0.170 \mathrm{a}$ \\
\hline & Cold-pressed & $8.190 \mathrm{~b}$ & $0.223 \mathrm{~d}$ & $4.103 d$ & $21.593 a$ & $64.613 f$ & $0.300 \mathrm{~d}$ & $0.127 \mathrm{f}$ & $0.160 a b$ \\
\hline \multicolumn{2}{|c|}{ Mean } & $8.230 \mathrm{~A}$ & $0.235 \mathrm{C}$ & $4.107 \mathrm{C}$ & $21.580 \mathrm{~A}$ & 64.795 D & $0.313 \mathrm{CD}$ & $0.132 \mathrm{C}$ & $0.165 \mathrm{~A}$ \\
\hline \multirow{2}{*}{ Merlot } & Solvent & $7.513 \mathrm{e}$ & $0.210 \mathrm{~d}$ & $3.660 \mathrm{c}$ & $17.350 \mathrm{f}$ & $70.500 \mathrm{a}$ & $0.347 \mathrm{~b}$ & $0.207 \mathrm{~b}$ & 0.167 a \\
\hline & Cold-pressed & $7.247 \mathrm{f}$ & $0.313 b$ & 3.843 ef & $20.937 b$ & $66.770 \mathrm{~d}$ & $0.317 \mathrm{~cd}$ & $0.203 \mathrm{~b}$ & $0.160 a b$ \\
\hline \multicolumn{2}{|c|}{ Mean } & $7.380 \mathrm{C}$ & 0.262 B & $3.752 \mathrm{E}$ & $19.143 \mathrm{C}$ & $68.635 \mathrm{~A}$ & $0.332 \mathrm{~B}$ & $0.205 \mathrm{~A}$ & $0.163 \mathrm{~A}$ \\
\hline \multirow{2}{*}{ Sangiovese } & Solvent & $7.217 \mathrm{f}$ & $0.337 \mathrm{a}$ & $3.733 \mathrm{fg}$ & $20.493 c$ & $67.387 \mathrm{c}$ & $0.380 \mathrm{a}$ & $0.173 \mathrm{~cd}$ & $0.163 a b$ \\
\hline & Cold-pressed & $6.947 \mathrm{~g}$ & $0.263 \mathrm{c}$ & $3.993 \mathrm{de}$ & $21.253 a b$ & $66.783 d$ & $0.313 \mathrm{~cd}$ & 0.143 ef & $0.170 \mathrm{a}$ \\
\hline \multicolumn{2}{|c|}{ Mean } & $7.082 \mathrm{D}$ & $0.300 \mathrm{~A}$ & $3.863 \mathrm{D}$ & 20.873 B & $67.085 \mathrm{~B}$ & $0.347 \mathrm{~A}$ & $0.158 \mathrm{~B}$ & $0.167 \mathrm{~A}$ \\
\hline \multirow{2}{*}{$\begin{array}{l}\text { Cabernet } \\
\text { Sauvignon }\end{array}$} & Solvent & $8.470 \mathrm{a}$ & $0.123 \mathrm{e}$ & $5.127 b$ & $17.123 f$ & $67.800 \mathrm{~b}$ & $0.300 \mathrm{~d}$ & $0.253 \mathrm{a}$ & $0.120 \mathrm{e}$ \\
\hline & Cold-pressed & $7.960 \mathrm{c}$ & $0.213 b$ & $4.500 \mathrm{c}$ & $20.100 \mathrm{~d}$ & $65.550 \mathrm{e}$ & $0.313 \mathrm{~cd}$ & $0.157 \mathrm{de}$ & $0.150 \mathrm{bc}$ \\
\hline \multicolumn{2}{|c|}{ Mean } & $8.215 \mathrm{~A}$ & $0.168 \mathrm{D}$ & $4.813 \mathrm{~B}$ & 18.612 D & $66.675 \mathrm{C}$ & $0.307 \mathrm{D}$ & $0.205 \mathrm{~A}$ & $0.135 \mathrm{~B}$ \\
\hline \multirow{2}{*}{$\begin{array}{l}\text { Sauvignon } \\
\text { Blanc }\end{array}$} & Solvent & $7.623 \mathrm{de}$ & $0.080 \mathrm{f}$ & $5.857 \mathrm{a}$ & $18.537 \mathrm{e}$ & $67.030 \mathrm{~cd}$ & $0.317 \mathrm{~cd}$ & $0.240 \mathrm{a}$ & $0.127 \mathrm{de}$ \\
\hline & Cold-pressed & $7.730 \mathrm{~d}$ & $0.117 \mathrm{e}$ & $5.983 \mathrm{a}$ & $18.280 \mathrm{e}$ & $67.060 \mathrm{~cd}$ & $0.330 \mathrm{bc}$ & $0.177 \mathrm{c}$ & $0.137 \mathrm{~cd}$ \\
\hline \multicolumn{2}{|c|}{ Mean } & $7.677 \mathrm{~B}$ & $0.098 \mathrm{E}$ & $5.920 \mathrm{~A}$ & 18.408 D & $67.045 \mathrm{~B}$ & $0.323 \mathrm{BC}$ & $0.208 \mathrm{~A}$ & $0.132 \mathrm{~B}$ \\
\hline \multirow{2}{*}{$\begin{array}{l}\text { Extraction } \\
\text { method }\end{array}$} & Solvent & $7.819 x$ & $0.199 \mathrm{Y}$ & 4.497 & $19.014 \mathrm{Y}$ & $67.539 X$ & $0.334 X$ & $0.202 X$ & $0.149 \mathrm{Y}$ \\
\hline & Cold-pressed & $7.615 \mathrm{Y}$ & $0.226 \times$ & 4.485 & $20.433 \times$ & $66.155 \mathrm{Y}$ & $0.315 \mathrm{Y}$ & $0.161 \mathrm{Y}$ & $0.155 \times$ \\
\hline \multicolumn{2}{|c|}{ D\%5 cultivar } & 0.109 & 0.011 & 0.095 & 0.225 & 0.225 & 0.012 & 0.012 & 0.008 \\
\hline \multicolumn{2}{|c|}{ D\%5 Extraction method } & 0.048 & 0.005 & N.S. & 0.099 & 0.099 & 0.005 & 0.005 & 0.004 \\
\hline \multicolumn{2}{|c|}{$\begin{array}{l}\text { D\%5 Cultivar X extraction } \\
\text { method }\end{array}$} & 0.174 & 0.017 & 0.151 & 0.359 & 0.359 & 0.019 & 0.019 & 0.013 \\
\hline
\end{tabular}

There were significant differences among the varieties in terms of the oleic acid content of grape seed oils (except for Sauvignon Blanc and Cabernet Sauvignon). The oleic acid content of all grape seed oils was significantly $(P<0.05)$ influenced by the extraction methods. The oleic acid content of the grape seed oils that were obtained by the cold-pressed method (20.43\%) was higher than that of the grape seed oils obtained by the solvent extraction method (19.01\%). Lutterodt et al. ${ }^{1}$ reported values for oleic acid between 13.19\% (Concord) and $21.9 \%$ (Ruby Red), Sabir et al..$^{20}$ between 18.31 (Red Globe) and 31.2\% (Hönüsü), Göktürk Baydar and Akkurt, ${ }^{4}$ between 17.8 (Emir) and 26.5 (Cavus).

The palmitic acid content ranged from $7.08 \%$ in Sangiovese to $8.23 \%$ in Sirah. Significant differences among the cultivars were determined in terms of the palmitic acid contents of the grape seed oils (except for the Sirah and Cabernet Sauvignon varieties). On the other hand, the variations between the palmitic acid contents of all the grape seed oils were found to be significant $(P<0.05)$ between the extraction methods. The palmitic acid contents of the grape seed oils that were obtained by solvent extraction $(7.82 \%)$ was higher when it was compared to the values of the grape seed oils that were obtained by the cold-pressed method (7.62\%). Göktürk Baydar and
Akkurt $^{4}$ reported palmitic acid values to vary between 6.5 and $9.7 \%$ in the Muscat of Hamburg and Rasacu varieties, respectively. Fernandes et al..$^{7}$ obtained values for palmitic acid ranging from $6.17 \%$ in the Periquita to $8.50 \%$ in Tinta Barroca variaties. Our results were in good accordance with these results. Additionally, the stearic and linolenic acid contents of the grape seed oils were in the range of 3.75 in Merlot - $5.92 \%$ in Sauvignon Blanc, 0.31 in Cabernet Sauvignon- $0.35 \%$ in Sangiovese. There were significant $(P<0.05)$ differences among the varieties in terms of their stearic acid contents, whereas no significant differences across the the extraction methods were found.

\section{Total Phenolic Contents (TPC) and Antioxidant Activity}

As presented in Table 3, the TPC were in the range of 115.68 for Sauvignon Blanc - $317.71 \mathrm{mg}$ GAE $/ \mathrm{kg}$ for Cabernet Sauvignon. There were significant differences across the varieties in terms of the total phenolic values of all the grape seed oils. Moreover, the TPC of all the grape seed oils was significantly $(P<0.05)$ effected by the extraction methods. The TPC values for the grape seed oils that were obtained by solvent extraction (253.04 $\mathrm{mg} / \mathrm{kg}$ ) were higher than those determined in 


\begin{tabular}{|c|c|c|c|}
\hline Cultivar & Extraction method & $\begin{array}{c}\text { TPC } \\
\text { (mg/kg GAE) }\end{array}$ & $\begin{array}{l}\text { DPPH radical scavenging effect } \\
\qquad(\%)\end{array}$ \\
\hline \multirow{2}{*}{ Sirah } & Solvent & $182.590 c^{*}$ & $26.333 \mathrm{~b}$ \\
\hline & Cold-pressed & $148.210 \mathrm{de}$ & $13.280 \mathrm{e}$ \\
\hline \multicolumn{2}{|c|}{ Mean } & $165.400 \mathrm{C}$ & $19.807 \mathrm{~B}$ \\
\hline \multirow{2}{*}{ Merlot } & Solvent & $148.527 \mathrm{de}$ & $17.517 \mathrm{c}$ \\
\hline & Cold-pressed & $151.510 \mathrm{~d}$ & $17.937 \mathrm{c}$ \\
\hline \multicolumn{2}{|c|}{ Mean } & $150.018 \mathrm{D}$ & $17.727 \mathrm{C}$ \\
\hline \multirow{2}{*}{ Sangiovese } & Solvent & $352.293 b$ & $27.290 \mathrm{~b}$ \\
\hline & Cold-pressed & $177.307 \mathrm{c}$ & $10.410 \mathrm{f}$ \\
\hline \multicolumn{2}{|c|}{ Mean } & $264.800 \mathrm{~B}$ & $18.850 \mathrm{BC}$ \\
\hline \multirow{2}{*}{ Cabernet Sauvignon } & Solvent & $452.997 \mathrm{a}$ & 53.593 a \\
\hline & Cold-pressed & $182.413 \mathrm{c}$ & $15.317 \mathrm{~d}$ \\
\hline \multicolumn{2}{|c|}{ Mean } & $317.705 \mathrm{~A}$ & $34.455 \mathrm{~A}$ \\
\hline \multirow{2}{*}{ Sauvignon Blanc } & Solvent & $128.813 \mathrm{e}$ & $7.240 \mathrm{~g}$ \\
\hline & Cold-pressed & $102.550 \mathrm{f}$ & $7.037 \mathrm{~g}$ \\
\hline \multicolumn{2}{|c|}{ Mean } & $115.682 \mathrm{E}$ & $7.138 \mathrm{D}$ \\
\hline \multirow{2}{*}{$\begin{array}{l}\text { Extraction method } \\
\text { mean }\end{array}$} & Solvent & $253.044 X$ & $26.395 X$ \\
\hline & Cold-pressed & $152.398 \mathrm{Y}$ & $12.796 \mathrm{Y}$ \\
\hline \multicolumn{2}{|c|}{ D\%5 Cultivar } & 12.191 & 1.155 \\
\hline \multicolumn{2}{|c|}{ D\%5 Extraction method } & 5.377 & 0.509 \\
\hline \multicolumn{2}{|c|}{ D\%5 Cultivar X extraction method } & 19.442 & 1.841 \\
\hline
\end{tabular}

the grape seed oils obtained by the cold-pressed method $(152.40 \mathrm{mg} / \mathrm{kg})$. To obtain the antioxidant potential of the seed oils from different grape varieties, DPPH radical scavenging activities were measured. As shown in Table 3, the DPPH radical scavenging activities of the grape seed oils ranged from 7.14 for Sauvignon Blanc to $34.46 \%$ for Cabernet Sauvignon. Significant variations among the varieties were found in terms of the DPPH radical scavenging activities of grape seed oils.

A-D express significant statistical differences between cultivars. X-Y letters express significant statistical differences between extraction methods. Different small letters express significant statistical differences the interaction of cultivars $\mathrm{X}$ extraction methods (Tukey test $P<0.05)$.

Furthermore, the DPPH radical scavenging activities of the grape seed oils showed significant $(P<0.05)$ variations between the extraction methods. The lowest DPPH radical scavenging activities were determined in the grape seed oils obtained by the cold-pressed method $(12.80 \%)$, while the highest values for the grape seed oils was obtained by solvent extraction $(26.40 \%)$. Apaydin et al. ${ }^{5}$ stated the total phenolic content values of grape seed oils to be varying between 1725 for Alicante Bouschet and $3330 \mathrm{mg} \mathrm{GAE} / \mathrm{kg}$ for Cabernet and the antioxidant activity was found in the range between 0.106 in Shiraz and $0.19 \mu \mathrm{mol}$ troloks / $\mathrm{g}$ in Cinsault for grape seed oils. Fernandes et al. ${ }^{7}$ reported values for DPPH radical scavenging activities to be ranging from 38.68 for Trincadeira Preta to $69.89 \%$ for Cornifesto. As previously reported by Lutterodt $e t$ al. ${ }^{1}$ the total phenolic content and the antioxidant activity of the grape seed oils that were obtained by the cold-pressed method varied between 160 for Ruby red and $800 \mathrm{mg}$ GAE/ $\mathrm{kg}$ for Concord, 0.07 in Chardonnay and $2.22 \mathrm{mmol}$ troloks / $\mathrm{g}$ in Concord, respectively.

\section{CONCLUSION}

The results of this study provide experimental data for the grape seed oils obtained by the solvent and coldpressed acquisition methods in terms of their fatty acid profiles, total phenolic content and antioxidant activity. Linoleic acid, which was the most abundant fatty acid, total phenolic content and antioxidant activity were found at the highest levels in the grape seed oils obtained by solvent extraction. On the other hand, the oleic acid values of the oils that were obtained with the cold-pressed methods was higher than those of the oils that were obtained by the solvent extraction method.

\section{Research Highlights}

There is no study about the effects of different extraction methods on fatty acid composition, total phenolic 
content and antioxidant activity of grape seed oil. The results of this study provides experimental data for the grape seed oils obtained by solvent and cold pressed in terms of fatty acid profile, total phenolic content and antioxidant activity.

\section{ACKNOWLEDGEMENT}

The authors are thankful to Hasan Ozkan Yorulmaz, $\mathrm{PhD}$ student, Mustafa Kemal University Institute of Science (Turkey), for antioxidant activity analysis.

\section{CONFLICT OF INTEREST}

The authors declare no conflict of interest.

\section{ABBREVIATIONS}

FAMEs: Fatty acid methyl esters; TPC: Total phenolic contents; DPPH: 2,2-diphenyl-1-picrylhydrazil; GAE: Gallic acid equivalents.

\section{REFERENCES}

1. Lutterodt $\mathrm{H}$, Slavin M, Whent M, Turner E, Yu L. Fatty acid composition, oxidative stability, antioxidant and antiproliferative properties of selected cold-pressed grape seed oils and flours. Food Chemistry. 2011;128(2):391-9.

2. Lachman J, Hejtmankov A, Taborský J, Kotíkova Z, Pivec V, Stralkova R, et al. Evaluation of oil content and fatty acid composition in the seed of grapevine varieties. LWT- Food Science and Technology. 2015;63(1):620-5.

3. OIV. World Vitiviniculture Situation. OIV Statistical Report on World Vitiviniculture. 20. http://www.oiv.int/public/medias/5479/oiv-en-bilan-2017. pdf

4. Gökturk BN, Akkurt M. Oil content and oil quality properties of some grape seeds. Turkish Journal of Agriculture and Forestry. 2001;25(3):163-8.

5. Apaydin D, Demirci AS, Gecgel U. Effect of Gamma Irradiation on Biochemical Properties of Grape Seeds. J Am Oil Chem Soc. 2017;94(1):57-67.

6. Rombaut N, Savoire R, Thomasset B, Castello J, Hecke EV, Lanoisellè E. Optimization of oil yield and oil total phenolic content during grapeseed cold screw pressing. Industrial Crop Prod. 2015;63:26-33.

7. Fernandes L, Casal S, Cruz R, Pereira JA, Ramalhosa E. Seed oils of ten traditional Portuguese grape varieties with interesting chemical and antioxidant properties. Food Research International. 2013;50(1):161-6.
8. Bail S, Stuebiger G, Krist S, Unterweger H, Buchbauer G. Characterization of various grape seed oils by volatile compounds, triacylglycerol composition, total phenols and antioxidant capacity. Food Chemistry. 2008;108(3):112232.

9. Xu C, Zhang Y, Wang J, Lu J. Extraction, distribution and characterisation of phenolic compounds and oil in grape seeds Changmou. Food Chemistry. 2010;122(3):688-94.

10. Bozdogan KD, Mungan B. Effects of variety, maturation and growing region on chemical properties, fatty acid and sterol compositions of virgin olive oils. J Am Oil Chem Soc. 2016;93(11):1499-508.

11. DaPorto C, Porretto E, Decorti D. Comparison of ultrasound-assisted extraction with conventional extraction methods of oil and polyphenols from grape (Vitis vinifera L.) seeds. Ultrasonic Sonochemistry. 2013;20(4):10761080.

12. Hanganu A, Todaflca MC, Chira NA, Maganu M, Roflca S. The compositional characterisation of Romanian grape seed oils using spectroscopic methods. Food Chem. 2012;134(4):2453-8.

13. Sevindik O, Selli S. The extraction methods of grape seed oil. Food. 2017;42(1):95-103.

14. Passos PC, Yilmaz S, Silva CM, Coimbra MA. Enhancement of grape seed oil extraction using a cell wall degrading enzyme cocktail. Food Chem. 2009;115(1):48-53.

15. Terigar BG, Balasubramanian S, Sabliov CM, Lima, Boldor D. Soybean and rice bran oil extraction in a continuous microwave system: From laboratoryto pilot-scale. J Food Eng. 2011;104(2):208-217.

16. Samaram S, Mirhosseini H, Tan CP, Ghazali HM. Ultrasound-assisted extraction and solvent extraction of papaya seedoil: Crystallization and thermal behavior, saturation degree, color andoxidative stability. Ind Crop Prod. 2014;52:702-8.

17. Lindy J. Supercritical fluid extraction technology, applications and limitations. Nova Science Publishers, New York: USA. 2015.

18. Teh SS, Birch J. Physicochemical and quality characteristics of cold-pressed hemp, flax and canola seed oils. Journal of Food Composition and Analysis. 2013;30(1):26-31.

19. AOCS. Official methods and recommended practices of the American oil chemists' society. AOCS Press 2003, Champaign.

20. Sabır A, Ünver A, Kara Z. The fatty acid and tocopherol constituents of the seed oil extracted from 21 grape varieties (Vitis spp.). J Sci Food Agr. 2012;92(9):1982-7.

21. Brand-Williams W, Culivier ME, Berset C. Use of a free radical method to evaluate antioxidant activity. LWT - Food Sci Technol. 1995;28(1):25-30.

22. Ozdamar K. Statistical Data Analysis with Package Programs, $1^{\text {st }}$ ed. Eskisehir. 1999

23. Shinagawa FB, Santana FC, Torres LRO, Mancini-Filho J. Grape seed oil: a potential functional food?. Food Sci Technol, Campinas. 2015;35(3):399-406.

24. Göktürk Baydar N, Ozkan G, Çetin E. Characterization of grape seed and pomace oil extracts. Grasas Y Aceites. 2007;58(1):29-33.

25. Tangolar SG, Ozogul Y, Tangolar S, Torun A. Evaluation of fatty acid profiles and mineral content of grape seed oil of some grape genotypes. International Journal of Sciences and Nutrition. 2009;60(1):32-9.

\section{Summary}

- Grape seed oils were extracted with cold-pressed and solvent extraction methods

- The quality characteristics such as fatty acid composition, the total phenolic content, antioxidant capacities were compared in the oil samples extracted by different methods.

- The total phenolic content and antioxidant activity values for the grape seed oils obtained by solvent extraction were higher than those determined in the grape seed oils obtained by cold-pressing. 


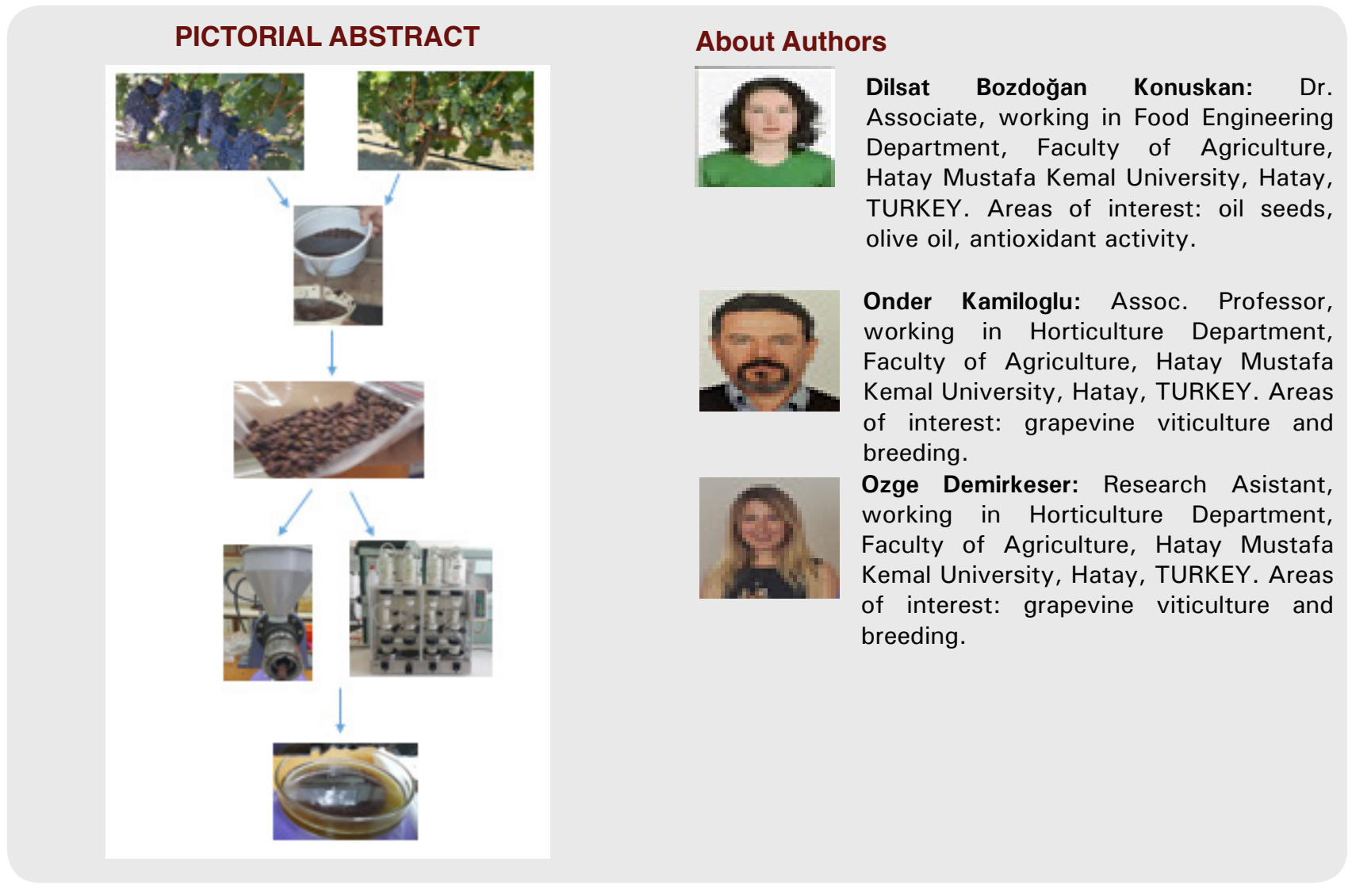

Cite this article: Konuskan DB, Kamiloglu O, Demirkeser O. Fatty Acid Composition, Total Phenolic Content and Antioxidant Activity of Grape Seed Oils Obtained by Cold- Pressed and Solvent Extraction. Indian J of Pharmaceutical Education and Research. 2019;53(1):144-50. 